\title{
Observations from the language classroom: The importance of the group
}

\author{
Francis J. Prescott \\ Károli Gáspár University, Hungary
}

DOI:10.14232/edulingua.2017.1.1

\begin{abstract}
The concept of group dynamics, coined by psychologist Kurt Lewin in the 1940s to describe behaviour in social groups, was first applied to the foreign language classroom in 1997 by Dörnyei and Maldarez as a way of exploring how group processes affect learning outcomes. This paper reports on a small-scale longitudinal case study of four university study skills classes for novice students and examines how the four teachers' differing approaches to group dynamics affected the students' experiences in those classes. The aim was to find what the differences were between the groups and to see what effect they had on the students' learning. The research was done over an entire academic year using semi-sructured qualitative interviews with both students and teachers, and the data (transcribed interviews) was analysed using the constant comparative method developed by Glaser and Strauss (1967). While the findings do not provide direct evidence that more cohesive groups promote better learning outcomes, they do indicate that students' enjoyment and engagement is enhanced in more cohesive classes, and that their attitude to their own learning is more positive. Furthermore, creating good classroom dynamics promotes skills which are also highly rated for $21^{\text {st }}$ century learning.
\end{abstract}

Key words: group dynamics, learning outcomes, qualitative interviews, constant comparative method, $21^{\text {st }}$ century learning

\section{Introduction}

As a scientific idea, the concept of group dynamics has been around for many years - it originated in the 1940s in the work of social psychologist Kurt Lewin, who found that the way a group was configured strongly influenced the behaviour of its individual members (Hergenhahn \& Henley, 2009, p. 459), and it was subsequently applied in many areas of sociology and psychology (Dörnyei \& Malderez, 1999). However, it took a great deal longer for the concept to be adopted by educationalists. In the world of the language teaching classroom, it was the importance attached to the communicative approach and cooperative learning that gave the impetus to examine the group dynamics of the language classroom in the 1990s (Dörnyei \& Malderez, 1997; Dörnyei \& Murphey, 2003). Now in the $21^{\text {st }}$ century there is a renewed emphasis on the need for learners to develop good communication and collaboration skills (P21 Partnership for $21^{\text {st }}$ Century Learning, n.d.; Trilling \& Fadel, 2009) and it may be time to take a fresh look at how fostering good group dynamics in and out of the language classroom can promote better learning.

This short paper looks at the way group dynamics may have affected learning in four first-year university classes held by teachers who had distinctly different 
approaches to group building. The idea for the paper grew out of my experience of observing the four teachers in their classes while doing my $\mathrm{PhD}$ research. Despite differing degrees of teaching experience, all four teachers had developed distinctive classroom practices, as well as a view of their own role as a teacher, which they were able to articulate clearly. Both in their words and in their actions there were marked differences between the ways they approached the culture of the classroom, and because I was also interviewing several of their students, I was able to get a two-way picture of what was going on in the classroom. This provided me with a fascinating insight into the group dynamics of each classroom, and I thought it would be worth exploring the topic in greater depth. However, the focus of my PhD (Prescott-Pickup, 2012) was on how the students adapted to academic writing requirements, so I could devote very little space to the culture of the different classrooms and the effect it had on the students.

The main aim of this paper is to examine what the differences in group dynamics were between the four classes and what the reasons were for them, and to look at the effect the classroom culture had on the students' learning in each case. Although the focus is on classroom learning, in the case of one teacher in particular, it will be seen that group dynamics involved creating a group structure which involved both in-class dynamics and out of class dynamics through the use of online communication. In this way the study is also connected to a more up-to-date view of how classroom dynamics can work in the digital age.

\section{Group dynamics in the language classroom}

It was Breen (1985) who first highlighted the neglect of the social nature of classroom language learning, and it was with Prabhu (1992) that a clearer understanding of the language classroom as a site of complex social interaction was first brought to notice. He drew attention to the fact that a classroom lesson, besides being an element in a planned curriculum and a way of implementing a particular method, is a social event and "an arena of social interaction" (p. 229) in which the teacher plays a crucial role. Prabhu claimed that in order to reconcile the potential conflict between these disparate aspects, it is necessary for the teacher to take into consideration the social dimensions of classroom life as well as the pedagogic ones. The teacher's role is essential to the establishment of routines that promote classroom stability and security, but for productive learning to take place, Prabhu called on teachers to become their own theorists rather than just implementers of the methods provided for them by specialists. This view of the teacher as theorist can be seen as part of the long discussion of the role of teachers and theorists in L2 education, a discussion which is still ongoing (e.g., Block, 2000; Labaree, 2003; Vanderlinde \& van Braak, 2010), but it is Prabhu's view of the way the teacher's personality affects the classroom dynamics which is of most interest here: "the teacher's own personality is a major factor in the interplay of forces, and conflict resolution will necessarily have to vary from one teacher to another" ( $p$. 
231). This points to the need for research to focus not just on finding the most effective teaching method for teachers to use, but also on understanding the complex interactions that actually take place in the language classroom. It is from this realisation of the foreign language classroom as a site of social interaction between learners and teacher that interest in group dynamics grew.

In their seminal 1997 article, Dörnyei and Maldarez argue that by an understanding of the principles of group dynamics, foreign language teachers can gain a much greater understanding of the characteristics and processes of their own groups and that this is worth doing because such characteristics and processes have a direct effect on the success or failure of learning outcomes. They also offer a number of practical suggestions (pp. 76-79) on how to exploit the principles of group dynamics for more effective L2 learning based on both the theory and their own teaching experience. Amongst these suggestions, they recommend using cooperative rather than individualistic or competitive learning tasks, including problem solving tasks, group projects and the writing of group reports, an approach that has a great deal of overlap with the currently popular $21^{\text {st }}$ century learning skills approach (Trilling \& Fadel, 2009). Dörnyei and Murphey (2003) also emphasize the importance of teachers devoting time to building cohesive groups in order to reduce the stress of teaching and to avoid teacher burnout as well as to promote more effective learning: "Learning about group dynamics and organising well-functioning groups will go a long way toward facilitating smooth classroom management and enhancing student performance" (p. 11). This need to pay attention to the cohesive functioning of the classroom group has been further emphasized and explored in the work of Rose Senior, which takes a social constructivist view of teaching and learning (2001; 2002; 2006). In her more recent work, Senior relates the kind of socially connected classrooms that effective teachers foster with the way effective online educators build online communities for distance learning, thus making the connection between successful learning in face-to-face classrooms and the skills needed for learning and cooperating in the $21^{\text {st }}$ century digital world (Senior, 2010).

The aim of the present paper is to explore the differences in the use of group building techniques by four university teachers in their classes and to show how these differences affected the classroom experience of both the students and their teacher. It also attempts to discover more about how group building can contribute to effective learning. The research involved a qualitative approach, so the next section will describe in greater detail how the study was conducted.

\section{Research methods}

The present paper relies on data from a much larger research study which was carried out for my $\mathrm{PhD}$. This section will only deal in detail with those aspects of the larger study which are relevant to the data discussed in this paper, namely, the observations 
and interviews involving the four Academic Skills (AS) teachers and their first-year students. That data was gathered as part of a longitudinal ethnographic study of how first year-students adapt to the writing requirements of university.

\subsection{Research setting and participants}

The research setting was the English Department of a large university in Budapest, and within this the weekly 90-minute AS classes which all new students studying English had to take over their first and second semesters. The main aim of these courses was to help the students adapt to the requirements of written academic discourse. The research was done by gaining access to four of these AS classes with the agreement of their teachers. In the first lesson of each class, the students were asked to fill in a short questionnaire asking about their English learning experience and with the questionnaire there was a letter of consent asking the students whether they were interested in participating in the research study. In all, 20 students, 4 to 6 students from each class, agreed to participate.

\subsection{Data collection}

The main method of data collection was long semi-structured qualitative interviews (McCracken, 1988; Prescott, 2011) which were conducted at intervals of roughly three months over the students' first three semesters studying English. A simple interview schedule was developed for each round (Maykut \& Morehouse, 1994), but the interviews gradually became longer and more free-flowing as the trust between interviewer and interviewee grew. The interviews were principally about the students' learning experience at the university, with particular attention paid to their writing assignments. Naturally, the writing that they did in the AS classes was also discussed, and in the course of these discussions their feelings about their learning experience in the AS course emerged.

In the first semester permission was also obtained to sit in as a participant observer on the four AS classes. Every single class was observed and I gradually became more of a participant and less of an observer. I took notes during and after each class using a simple observation protocol (based on Creswell, 1994) which focused on teacher-student interaction and teacher talk. Being accepted into each class in the role of both an observer and a participant was important because it gave me the opportunity to learn much more about the culture of each class from the perspective of the participants (DeWalt \& DeWalt, 2002).

I was also interested in the perspective of the four teachers, and whenever possible I discussed each lesson with the teacher immediately after the class was over. However, this depended on how much time I and the teacher had available. In some cases it proved possible to meet the teacher later in the week to discuss the class. Such short 
informal conversational interviews (Patton, 2002) focused on points of interest arising from the class, but could also be used to explore the teacher's views of his or her students' progress and general feelings about how the course was developing. No preplanned interview protocol was used for these discussions and, in order to keep them relaxed and informal, they were not recorded. I wrote down brief notes during the discussions and added to them afterwards.

Three of the teachers ${ }^{1}$ also agreed to do much longer recorded interviews after the end of the students' second semester. These interviews were well over an hour long and covered all aspects of their teaching of the course. A validated and piloted structured interview protocol was used, following McCracken's guidelines for ethnographic interviews (1988).

\subsection{Data analysis}

All the interviews were transcribed and sent to the interviewee for member checking. The constant comparative method of data analysis first described by Glaser and Strauss (1967) in their ground-breaking work on making qualitative research more rigorous was used as the basic approach. A clear and succinct description of the basic method is given by Saldana (2009). It involves breaking down the data into simple data chunks, each of which represents a concept in the data. These coded concepts are then used to build up more complex categories and the relations between the categories are described, until a clear picture of the phenomenon under investigation is achieved.

\section{Results and discussion}

Before looking at each teacher individually, it is important to point out that multiple factors are at play in any classroom that can affect the group feeling, and it is certain that the teacher cannot control all of them. Moreover, as with any piece of social scientific research in everyday contexts, the reality under investigation cannot be neatly controlled by the researcher either. Nevertheless, such research is worth doing as it can give an in-depth insight into particular contexts which can then be compared with other similar contexts (a notion termed transferability by Guba (1981)), and even in a short study such as this, it is possible to distinguish some salient differences between these teachers which clearly had an effect on the way the students saw the course.

One further point that is worth mentioning is that for any teacher who wants to create positive group dynamics in their class, the job is made more difficult by the fact that the class is only held once a week and the students in each AS class mostly do not meet each other in their other classes. Moreover, as noted by an expert AS teacher (interviewed in the initial stages of the research) who had been involved with the AS

\footnotetext{
${ }^{1}$ Teacher A was on maternity leave at that time and later went to work in another country.
} 
course from its inception, there was a problem with the students having a negative perception of the course: "I don't know if this is a weakness of the course or a weakness of us teachers - I can still feel that students are not so terribly happy about this course" (Interview with an expert AS teacher, pp. 10-11). As will be seen, this unhappiness with the course actually tended to vary from student to student, but it was certainly palpable in some students, especially the more able ones who tended to be dissatisfied with doing more basic activities.

\subsection{Teacher A}

Teacher A was the least experienced teacher of the four. She was in her second year as a university teacher and most of her experience of AS came from her time as a student at the same university rather than from teaching it. She tended to use the same approach throughout the semester: the students sat in a circle with her (this seating arrangement never varied) and they would work from handouts that she gave them. The students did tasks in pairs or small groups and then she would conduct whole-class feedback by going through the questions and asking additional ones.

The problem with this approach is that it did not result in much interaction between students and teacher or between students and other students. Several times in my observation notes, I was aware of long pauses and lack of responsiveness on the students' part when the teacher asked questions. The students too were aware of this problem with the stilted nature of the interaction in the classroom. One student, Brigi ${ }^{2}$, put it in the following way: "I would make it more interactive. So more speaking and debating ... because it was a little bit boring. Because the teacher said what she wanted to say and we read the papers, but we couldn't share our ideas" (Brigi, Interview 3, p. 2). Another student, Erika, also grew tired of the repetitive nature of the classes: "So sometimes I feel a bit bored or, so it's, well, it's always the same and always the same structure and always the same form" (Erika, Interview 2, p. 1).

It was clear that the teacher herself frequently found it very difficult to elicit answers, having to use probes repeatedly. In conversation after her classes, she was aware of this problem but talked about it in terms of students as either being contributors or being quiet. She also said that she preferred students to volunteer but if nobody volunteered then she picked someone (Teacher A, Post-class discussion, Week 4). Teacher A's classes were always teacher led with her doing most of the talking. This was very likely exacerbated by the difficulty of getting significant contributions from more than a handful of students. By Week 4 she knew who the main contributors were, naming three in the post-class discussion. One of these contributors, Viki, actually became progressively less keen to interact in class, and her reason gives an insight into what might have been holding back other students, as well:

\footnotetext{
${ }^{2}$ Since the students and their experiences were the main focus of the research, each one was given a pseudonym.
} 
Sometimes I'm trying to interact but sometimes I feel that I shouldn't because maybe I cannot say the thing our teacher is thinking about, and I will be /?/ the others and saying things that are misleading. So sometimes I just don't want to answer because of this. (Viki, Interview 2, pp. 1-2)

She was particularly conscious of the mixed ability of the group: "So we are very different on this course. I mean there are those who don't speak fluently and there are some who have written many many essays, and know what [an] argumentative essay is" (Viki, Interview 2, p. 2). As a result, she had taken the decision that she would rather be a listener than a talker. A much weaker student ${ }^{3}$, Csenge, felt a similar inhibition about speaking in front of the group:

I think sometimes we are not sure about the question, or about the task, and that's why nobody want to talk about it or just raise a hand and say something. And because nobody want to talk, you know, there is a complete silence, anybody want to break it. So - or nobody want to break it I mean. (Csenge, Interview 2, p.10)

This inhibition felt by weaker and stronger students is a clear sign that Teacher A was unable to create a group dynamic that encouraged collaboration in her classroom in spite of her efforts to do so. At the time she also seemed unable to take any effective steps to overcome this inhibition or to even clearly identify the nature of the problem the situation had not changed by the end of the first semester. However, with more experience it is to be hoped that she would be able to use more variety in her teaching methods and find more successful techniques for fostering classroom interaction.

It should also be pointed out that, despite the lack of interaction during the classes, the students still felt that they learnt a lot during Teacher A's course. For instance, Brigi, looking back on the first AS course at the beginning of her second semester, said that she felt the course had been useful because she learnt how to build up a paragraph and then an essay, and it helped with other writing assignments that she had to do (Brigi, Interview 3, p. 2).

\subsection{Teacher B}

Teacher B had considerable teaching experience and had been involved with the AS course since its beginning, first as a student and then as a teacher. However, he too experienced problems with creating good group dynamics in his AS classes, and he was quite open about this: "I know that I have group dynamics problems, partly again because it's one course per week" (Interview with Teacher B, p. 12). He felt that in

\footnotetext{
${ }^{3}$ Csenge knew that she had basic problems with her grammar right from the beginning of the study when she filled in the initial questionnaire. In answer to question 8, which asked if there was anything in particular that she needed help with in her writing in English, she mentioned "use of tenses" and "more accurate work" (Csenge, Student Questionnaire).
} 
classes where he met the students twice a week (he had one such class at the time, a Language Practice class) he was able to do a better job of creating good group cohesion:

I had time to find out about people and then we had interesting discussions about each other and then, at the end, I could feel that we are a sort of family ... So this kind of group dynamics is not given in the AS classes, partly because I'm sort of frugal (laughs) I don't want to spend time [on it]. (Interview with Teacher B, p. 12)

The point about not wanting to spend time on building good group dynamics was indicative of a conscious decision on Teacher B's part to spend his limited class time on teaching the subject matter. It also indicated that he saw group dynamics as being a peripheral concern to the main business of his classes, an optional extra. He clearly realised that good group dynamics was a desirable quality for a class to have, but he did not see building a cohesive group as an important part of the learning experience of his students, other than for purposes of getting students to give each other feedback: "I know I should do more in terms of group dynamics, and group dynamics is important because it actually rewards you when you have feedback, when you have peer revision for example" (Interview with Teacher B, p. 12). Not surprisingly, he used "very little peer feedback" (p. 12). He also said he thought his students were used to being in classes in which they did not know each other's names, and, therefore, "they don't even seek the kind of interaction or they don't want to get to know one another so very well, $I$ think" (p. 12).

From the students' point of view, Teacher B's classes were described as being useful but not very interesting. All five of the students interviewed from this class spoke either of the teacher's expertise in the subject or of the need to learn writing skills, and Vilmos, Zsuzsa, Natalie, and Gergely mentioned choosing Teacher B's group because it had been recommended to them by older students. However, three of the students said they sometimes found the course boring. Both views are reflected in Fiona's observation:

Well it's OK. I find it lots of times boring. I don't know. Well I think Teacher B does it well. I mean he knows what he's doing and he's really into whatever but I don't think it's a very interesting class. So I know it's probably good for writing skills or whatever but... (laughs). (Fiona, Interview 1, p. 2)

Zsuzsa said she liked the lessons and thought the teacher was good but she also felt that sometimes they were uninteresting:

I mean the lesson sometimes is very boring. Well not boring just, we are just sitting there, and listening to the teacher and nothing happens, he just talks. And, and, it's not the kind of topic which we're interested in. (Zsuzsa, Interview 3, p. 2) 
Vilmos also had mixed feelings: he found the classes necessary but "a bit boring" (Vilmos, Interview 1, p. 4). Another student, Gergely, while not saying that he found the classes boring was not very enthusiastic about them. He found the course "quite useful" (Gergely, Interview 2, p. 1) and said the group was "okay" in the same interview. He was much less forthcoming in his interviews than most of the other students and tended towards the minimal in his responses, but in a later interview it seemed clear that he sometimes found the classes not to be very enjoyable, as well: "Yeah I would say sometimes it was good. Sometimes not (Laughs)." (Gergely, Interview 3, p. 2).

This mixed response corresponded very closely with what the teacher himself said about the need to spend the limited time available on teaching the subject material rather than building good group dynamics. All the students seemed to recognise the usefulness of the course content, although for the most able students the perceived pace of the course was part of the problem. Vilmos and Fiona were both significantly ahead of the other students in terms of their general proficiency in English. Vilmos had learnt English mostly outside high school from the South African wife of one of his father's friends and from doing voluntary work for a charitable organisation for four years, translating the annual budget from English into Hungarian and spending two months in the organisations international office in the south of England. Fiona came from a highly academically oriented family (her parents and her sister had all attended university), who all spoke English and she had spent two periods living in the USA during which she attended the $1^{\text {st }}$ and $6^{\text {th }}$ grades at school.

Both these students had a high level of spoken English but did experience some problems with their writing. Vilmos did not like having to do obligatory writing tasks. However, when his internship with the charitable organisation had ended unexpectedly early in December, he had started university in the spring semester of the previous year, rather than waste valuable time, and had found himself having to write four seminar papers without having had any preparation. The fact that he was able to do this and managed to get a pass grade in three out of the four subjects that he wrote the papers for was an indication of both his proficiency in English and his resourcefulness as a student. He appreciated the AS course because he knew it was providing him with the help that he had lacked in his first much more difficult semester, but still he found the course very slow:

It's absolutely necessary because I know the, my desperation from last semester when I had to write four seminar papers and then I didn't have any idea how to write an essay or anything which is academic in style. And so, yeah, I find it completely necessary but I'm not interested in it at all. So it's a bit like ambivalent, or contradictory. And, yeah, I find the classes a bit boring. (Vilmos, Interview 1, p. 4)

One factor beyond Teacher B's control which may have negatively affected the dynamics in the class was the room. Out of the four classes I observed, Teacher B's was in the smallest room and this meant that it would have been very difficult to change the 
seating arrangement, which was a U-shape with the teacher's desk at the top in front of the blackboard. This arrangement allowed the teacher to walk around in the middle of the U-shape to talk to individual students, but made it quite difficult for the students to move around on the outside of the $\mathrm{U}$, with the result that when pair or group activities were done, students tended to work with others close to them if they could, thus limiting the amount of interaction during the classes. There were occasions when the teacher made an effort to get mixed groups, as in the second week when he assigned each student a number from one to four and they had to work with the other students with that number. However, this was the exception rather than the rule, probably because it took time for the students to arrange themselves in their new groups, a fact quickly noticed by the teacher: "Okay, now this takes ages!" (Teacher B, Classroom Observation 2, p. 3).

One result of this relatively static seating arrangement is that the students did not seem to know all the other students' names (there were 12 of them altogether). This was something that several of the students commented on half way through the course: "I find that sometimes I find it quite difficult to communicate with the others, especially because I usually sit, actually almost everybody sits in the same place" (Vilmos, Interview2, p. 1). Fiona felt she only knew the student who was in another of her courses: "We don't talk much, I mean, with each other. I don't really know any of them. Well there's just one guy who I'm in with two other seminars and that's it" (Fiona, Interview 2, p. 2). Natalie also mentioned that she only knew those students who she shared another seminar with.

Teacher B's content-focused approach demonstrated that a competent and experienced teacher may choose to more or less ignore group dynamics and still be able to teach the content of the course effectively. Nevertheless, it was clear from his students' interviews and from my own observation of his classes that at times there was a distinct lack of energy, and when the students were required to work together they did so without enthusiasm. It was also clear that, although the students may have appreciated the usefulness of the content, they sometimes did not enjoy the classes.

\subsection{Teacher $C$}

Teacher $\mathrm{C}$ had taught English as a foreign language for several years in private schools and for the British Council. He was a very experienced teacher but his style of teaching was influenced by his years of TEFL ${ }^{4}$. His lessons were tightly planned with a variety of tasks which involved group, pair and individual work. Sometimes he would make an activity more interesting and interactive by doing it in an unusual way. One example of this was the peer evaluation activity he did in the second class with the short essays the

\footnotetext{
${ }^{4}$ In fact, Teacher $\mathrm{C}$ identified his teaching style as "a beneficial amalgam of the academic approach plus the EFL approach" (Interview with Teacher C, p. 9) as he had begun his teaching career in the university sector.
} 
students had written in the first class. The teacher stuck the essays all around the classroom and gave each student a post-it note. After brainstorming what makes a good essay as a whole class, everybody had to read someone else's essay and write some feedback on the post-it, sticking it on the essay when they had finished, and then going on to another essay. At the end the teacher asked them to add to the ideas already on the board about the characteristics of a good essay using the feedback they had written and read (Teacher C, Classroom Observation 2, pp. 2-4). This was an unconventional way of handling peer evaluation in an AS class but the students clearly found it an enjoyable and interesting activity. It also proved to be an effective way of raising some key ideas about what an academic essay should be like.

One of the students, Emily, had attended a private language school in England and she very quickly recognised the TEFL style: "When I first came in, I felt like I'm back in that school ... where I studied. It was like, this Academic Skills class is like being in a, or attending a, like a high quality language group" (Emily, Interview 1, p. 4). Emily was clearly very impressed by Teacher $\mathrm{C}$, particularly his use of humour, something which was often noticeable in the classroom observations, too, for instance, in the way Teacher $\mathrm{C}$ introduced the very first class: "This will be a short class, not short short but shortish" (Teacher C, Classroom observation 1, p. 1). As a prospective teacher herself she regarded him as a good role model:

I'm hanging on all the words [Teacher C] is saying. Finding it very funny actually he keeps making jokes. And I would like to actually - I thought of making notes of how he's teaching because I think it's just brilliant and he's a very good teacher. (Emily, Interview 2, p. 2)

The way Teacher $\mathrm{C}$ used his TEFL experience to create interesting classes with frequent variations of pace and style was appreciated by the other students, too. Krisztina also really enjoyed the course: "Oh I like it very much. I think Teacher $\mathrm{C}$ teaches very well. I like the lessons cos they are quite enjoyable and everyone gets included into the lesson so that's good" (Krisztina, Interview 2, p. 2). She particularly liked the emphasis on giving peer feedback on each other's writing: "I liked the way he teaches us. I think it's really good that we can see each other's works, and we can talk about how we should be better. I think it's very effective" (Krisztina, Interview 3, p. 2). She also felt that the course had helped her with the seminar papers she had to write in her other courses and that she had made progress with her writing.

Both Richard and Steven had done very little writing at school. Richard said he had "had a bad teacher. Mainly the past two years. So I really learnt at home in English" (Richard, Interview 1, p. 1). Steven also felt that his English classes were not very good: "we didn't really study English very well ... And we didn't really have to write essays, nothing like that" (Steven, Interview 1, p. 1). Consequently, both of them experienced difficulty with their English studies and with writing in particular, but again they both enjoyed Teacher C's course and felt that it helped them. Richard felt that Teacher C was 
"a bit severe with things like homework" (Richard, Interview 1, p. 2), but he acknowledged that it was his problem because he had not done the homework and he liked the teacher's approach which he described as "fun" (p. 2). Steven was worried about not being good enough to succeed in his studies. This feeling was particularly exacerbated by the awareness of other students who were much better at English than he was: "and they speak English pretty good. And I'm not so good. And I have this fear that I, maybe I won't be good enough" (Steven, Interview 1, p. 2). Because of this he appreciated the amount of practice that he did in Teacher C's classes and particularly the feedback he received on his writing:

... we had to write this essay for about 500 words, or something like that. And then we got it back and there were a lot of signs $-\mathrm{p}$ and $\mathrm{v} f$ and everything, what we should practice. And that's a great thing I think, especially for me because I have to know what my weaknesses are. And so I can see. And practice them. (Steven, Interview 1, p. 3)

Looking back on his first semester, Steven was aware of the difference in the way the course was conducted and its effectiveness: "And since I never had earlier such lessons, I don't have anything else to compare with, but I suppose it was quite effective, and I learnt how to write, so I really appreciate that course. So positive feelings" (Steven, Interview 3, p. 2).

In addition to the careful planning of the classes, Teacher $\mathrm{C}$ was conscious of the need to create good interactions between his students in the classroom. This was partly because of his view of the course as being more than just about teaching the students academic skills: "I do think that the 104 [AS] course should be more of an introduction to university life and what it means to be a student" (Interview with Teacher C, p. 2). He was very aware of the difficulty many students had in making the transition from school to university, and he thought the AS course was the right place to give them some assistance:

So I think the first semester should be, you know, sitting down with the students, talking about what courses they teach, [sic] what combinations they have, how they're going to organise their life, their academic life, their personal life, maybe their working life because that's an issue which I think is becoming more and more significant here. Lots of students are studying at other places, lots of them are doing double majors, lots of them are working at the same time. (Interview with Teacher C, p. 3)

He felt that students often were unaware of the formal requirements of their new role: "that if they're at university they're expected to fulfil a certain role with a certain function, and as a teacher I'm there to perhaps guide them and help them if possible" (Interview with Teacher C, p. 3). However, he found it very difficult to do this 
alongside teaching the necessary content that he had to cover: "I try to discuss these issues, specifically in the first half of the semester, ... but again it's always, there's always the course content hanging over all our shoulders, or over all our heads" (Interview with Teacher C, p. 3).

This view closely echoes the feelings of Teacher B; however, Teacher $\mathrm{C}$ put much more emphasis on good group dynamics: "I think group dynamics is an important area. ... I do try to create a cohesive group. I do try and bring everybody in" (Interview with Teacher C, p. 9), and he felt that the techniques he had picked up during his years in private language teaching helped him "change the whole dynamic of the group, positively. And make my life probably easier and be more entertaining and useful and productive for the students" (p. 8). This certainly seemed to be borne out by the responses of his students. Thus, Teacher $\mathrm{C}$ was both similar to Teacher $\mathrm{B}$, in his concern for teaching the required academic content of the course, and in contrast to him, in his concern for creating a good classroom experience for his students and believing it worthwhile to do so. And both of the teachers' approaches and worries were evidence of the conundrum of having to make difficult decisions about how to use limited classroom time in the most effective way.

\subsection{Teacher D}

For Teacher D, creating a strongly cohesive group and building student confidence was central to his approach to the course, and consequently he did more to develop good group dynamics than any of the other teachers. He wanted to help his students develop the skills they needed to write academic essays but he also wanted to foster the students' ability to think for themselves: "I like to encourage a thinking-for-themselves attitude. I don't like spoon-feeding them, you know. I don't like - my views of education are to do with discovery, self, you know, with finding out" (Interview with Teacher D, p. 4). He saw the ability to work effectively with others and take risks as a necessary part of discovery learning: "And then to do with group, working in a group or to develop a safety in the group, that they can share ideas and work together" (Interview with Teacher D, p. 4), an approach which closely resembles the emphasis put on cooperative learning in the 21st century learning skills model.

It was clear from the views of his students that he was very successful in his aim of building a group where the students felt secure and able to work together. All of the students who took part in the research expressed very positive feelings about the course. Jane, a highly academic student whose mother and father had also gone to the same university, felt that the AS course was "one of my best in all the courses at the university" (Jane, Interview 2, p. 1). For her the group was "the best English group I have" (Jane, Interview 2, p. 1) in stark contrast to her Linguistics group, which she described as a "catastrophe" (ibid) in comparison. Alice also came from an academic background. She particularly enjoyed the interaction in the group: "I like this because 
it's very interactive, and I don't feel like at the other courses, that I'm sitting there, looking at the teacher and trying to pay attention" (Alice, Interview 1, p. 3), and in the same interview she said she didn't want the course to finish. Tibor was equally positive: "I think it's great" (Tibor, Interview 1, p. 3). He felt that "this group is not concentrating really on the boring part of this academic skills. I think another teacher could do it in a very boring way but he's not boring" (ibid). This statement is interesting because while it reveals a negative view of the subject matter, a phenomenon already mentioned as being a problem with the image many students had of the course, at the same time it shows that the course could be taught in an interesting way.

Monica had a class just before AS that she did not like and she found Teacher D's class made her feel better:

I enjoy it very much. It is very friendly. It is very good because before that course I have Linguistics which isn't so enjoyable and after that lesson I always feel: 'Oh, I'm not suitable. I don't want to /?/. And it ends at 10 o'clock and Academic Skills starts at 10 so just right after that lesson comes this lesson. And then it makes me stronger that I enjoy it. That lesson. So it is very /?/ me. And I think that's the only course where I know the people around me. So it's good. (Monica, Interview 1, p. 3)

The positive effect that Teacher D's course had on Monica is clear from this quotation and since she had chosen this particular AS course only because it fitted her timetable, she felt very lucky that she had got such a good teacher. By contrast, Julie deliberately chose Teacher D's course because she had been told at the Freshers' Camp that he was a good teacher. She was doing a double major and in the first semester she too had problems with some of her other courses, particularly with the reading she had to do, but similarly to Monica, she felt that the AS course helped her:

So I always look forward to that one hour and a half because it's not so strict but it's very helpful I think. And not just - so I like it that it's not just about one topic but it's mostly about how to help us to improve. And I think it's very useful and no-one else takes care of this. (Julie, Interview 1, p. 4)

She also very much appreciated being in a group where she felt secure: "It's like coming into a small family or I don't know what. It's a great place and I'd like to stay there next semester too, because it's very, very good" (Julie, Interview 2, p. 2).

Teacher D was able to achieve this remarkable degree of group cohesiveness through a number of techniques which he used, but most of all through his own interaction with his students. He spent a lot of time on developing a cohesive group both through the way he organised his classes and by getting students to work together and to feel that they were part of a group that was more than the sum of its parts. One of the ways he achieved this was to always take notice of students who were absent or late and get other students to notice as well: “Are we all here, right? Can anyone think who's 
missing?" (Classroom Observation Notes, Week 2, Teacher D, p. 1), and in the informal interview after the fifth class he said that he discussed people being absent to develop group respect and to remind the students that he wanted them to be in the classes (Classroom Observation Notes, Week 5, Teacher D, p. 9). He also encouraged his students to contact him by email between classes with questions or when they were working on writing tasks and wanted more help. He saw this as a way of giving them individual attention and also helping to develop their language ("they can write without fear of making mistakes - they're not being marked" (Classroom Observation Notes, Week 13, p. 11) as well as developing a better relationship with his students.

For Teacher D the group itself was the key to successful learning. He felt that building good relationships within the group had a direct effect on the quality of learning in the class:

I think if people don't know anybody in the class I don't see how you can have a decent discussion. Cos there's no trust between anybody, you know, people are worried about saying things or they don't feel like saying things. So, you know, to actually create an atmosphere where they're happy to go there, they don't feel stressed out, they don't feel worried about making a fool of themselves or speaking out. I think that's really important. (Interview with Teacher D, p. 16)

Everything that happened in each of his classes was deliberately designed to create a positive feeling in his students and to encourage them to support each other and to cooperate:

I think it's from the beginning when they walk in, you know, the way that you behave towards them, the way you create an atmosphere in the class with either a bit of a song or something that's going on in the world that you bring in, something that's different, and you create a - there's always something unexpected that happens, you know, that people look forward to coming. And then you encourage them to help each other with the work that they do. You talk about 'Could you get together and work on this together?' and see, you know, sometimes that's possible, sometimes there are people who are big individualists and they don't do that. But most of them do, if you encourage that. (Interview with Teacher D, p. 17)

His ability to build a fully cohesive group and make his classes something that the students positively looked forward to showed that, in spite of the course being just once a week and students being used to other classes where it was usual that they did not know each other, it was possible to have very good group dynamics. Moreover, the learning experiences of his students were indicators that this also had a significant positive effect on students' learning. For example, peer feedback activities were very successful in his groups and several students commented on how effective they felt the writing activities had been in helping them understand what was required at this level: 
I guess the first, so basically what's about essays we learned in the first seminar, the first semester, with Mark, and those things of course still helped me because that's when we got the foundation of essay writing and I think that's gonna help me for years and years because we, he taught us this. (Julie, Interview 5, p. 6)

The other students said very similar things about how the course helped them with their writing; for instance, Monica said: "I feel that I could achieve improvements in writing /?/ and the whole lesson will help us I think" (Interview 2, p. 4), and Tibor, who had problems with organisation and writing to the required length also felt that "my essays improved" and that his last piece was better organised (Interview 2, p. 5). Even Jane, who had participated successfully in a national academic competition in which she had to write a long essay, felt that she benefited from the course. While she did not find the writing tasks difficult, she appreciated the teacher's interactive approach to discussing them:

Well I think it is very good and not very difficult. But I really like that Mark tries to discuss the problems and does not usually discussing like the teacher tells us how to write, but we have to correct mistakes. (Jane, Interview 2, p. 5)

Teacher D was the teacher who put the most emphasis on creating good group dynamics and it was very clear from the reactions of his students that he was successful. Because of this he was able to win the students trust and get them to try different approaches which created valuable learning opportunities and outcomes. His class shows how good group dynamics can be a powerful support for learning, something that the literature on $21^{\text {st }}$ century learning skills also seems to suggest in its call for students who can cooperate in complex learning tasks.

\section{Conclusion}

If the enjoyment and engagement of the students are important to successful learning in the language classroom, then teachers cannot afford to ignore the need for building cohesive groups, groups that encourage and motivate students because they enjoy being a part of them and which, therefore, enhance their learning experience. Clearly it is not possible to generalise from a sample of just four classes, but what is clear from these indepth case studies is the effect each teacher's approach to group dynamics had on the students' experience of and attitude to the course. The research also shows how important it is to get the students' perspective on what goes on in the classroom. In this study, the differences in the students' experiences show clearly the effect of not paying attention to group dynamics or not knowing how to foster cohesion within a group. In all of these classes the students reported that what they learned was useful to them, but there was a clear divide in terms of motivation and engagement between those classes where the teacher created a strong group feeling and those where he or she did not. 
Cohesiveness is particularly relevant to language classes where cooperation and trust are desirable for more effective learning to take place, such as when doing communicative activities and when asking students to do peer evaluation in writing classes. Moreover, in the $21^{\text {st }}$ century the need for cooperation, communication and flexibility are at a premium, and so creating good classroom dynamics is more than just an incidental extra - it should be a key part of the learning experience of all students at every level of education. Teachers should be paying much more attention to how to create cohesiveness in order to better facilitate cooperation and communication, especially in language classes, and nowadays it is a lot easier to develop close learning relationships both within and outside the class using the affordances of digital technology. Modern teachers can no longer afford to view group dynamics as something optional - it has to be an integral part of the learning process, all the more so when communication skills are at the centre of the learning aim and when education has to prepare students to be successful in the digital world of online connectivity.

\section{References}

Block, D. (2000). Revisiting the gap between SLA researchers and language teachers. Links \& Letters 7, 129-143.

Breen, M. (1985). The social context for language learning - A neglected situation? Studies in Second Language Acquisition, 7(2), 135-158.

Creswell, J. W. (1994). Research design - qualitative and quantitative approaches. Thousand Oaks, CA: SAGE.

DeWalt, K. M., \& DeWalt, B. R. (2002). Participant observation: A guide for fieldworkers. Walnut Creek, CA: AltaMira Press.

Dörnyei, Z, \& Malderez, A. (1997). Group dynamics and foreign language teaching. System, 25, 65-81.

Dörnyei, Z., \& Malderez, A. (1999). The role of group dynamics in foreign language learning and teaching. In J. Arnold (Ed.), Affect in language learning (pp. 155-169). Cambridge: Cambridge University Press.

Dörnyei, Z., \& Murphey, T. (2003). Group dynamics in the classroom. Cambridge: Cambridge University Press.

Glaser, B. G., \& Strauss, A. L. (1967). The discovery of grounded theory: Strategies for qualitative research. Chicago, IL: Aldine.

Guba, E. G. (1981). Criteria for assessing the trustworthiness of naturalistic inquiries. Educational Communication and Technology Journal, 29(2), 75-91.

Hergenhahn, B.R., \& Henley, T.B. (2009). An introduction to the history of psychology. Belmont, CA: Wadsworth. 
Labaree, D. F. (2003). The peculiar problems of preparing educational researchers. Educational Researcher,32(4), 13-22.

Maykut, P., \& Morehouse, R. (1994). Beginning qualitative research: A philosophic and practical guide. London, England: The Falmer Press.

McCracken, G. (1988). The Long Interview. Newbury Park, CA: SAGE.

P21 Partnership for $21^{\text {st }}$ Century Learning (n.d.). Retrieved from http://www.p21.org/index.php

Patton, M. Q. (2002). Qualitative research and evaluation methods (3rd ed.). Thousand Oaks, CA: SAGE.

Prabhu, N. S. (1992). The dynamics of the language lesson. TESOL Quarterly, 26(2), 225-241.

Prescott, F. J. (2011). Validating a long interview schedule. WoPalP (Working Papers in $\begin{array}{lllll}\text { Language } & \text { Pedagogy) } 17-37 . & \text { Retrieved from }\end{array}$ http://langped.elte.hu/WoPaLParticles/W5Prescott.pdf

Prescott-Pickup, F. J. (2012). Adapting to the requirements of written academic discourse on entering university (Unpublished doctoral dissertation). Eötvös Lóránd University, Budapest, Hungary.

Saldana, J. (2009). The coding manual for qualitative researchers. Thousand Oaks, CA: SAGE.

Senior, R. M. (2001). Creating safe learning environments: Developing and maintaining class cohesion. Intercultural Education, 12 (3), 247-259. DOI: 0.1080/14675980120087462

Senior, R. M. (2002). A class-centred approach to language teaching. ELT Journal, 56(4), 397403.

Senior, R. M. (2006). The experience of language teaching. Cambridge, UK: Cambridge University Press.

Senior, R. M. (2010). Connectivity: A framework for understanding effective language teaching in face-to-face and online learning communities. RELC Journal, 41(2), 137-147.

Trilling, B., \& Fadel, C. (2009) $21^{\text {st }}$ century skills: Learning for life in our times. San Francisco, CA: Jossey-Bass.

Vanderlinde, R., \& van Braak, J. (2010). The gap between educational research and practice: Views of teachers, school leaders, intermediaries and researchers. British Educational Research Journal, 36(2), 299-316. 